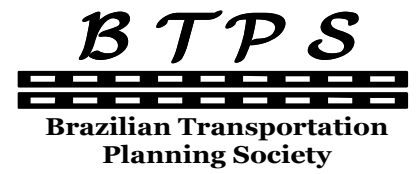

Planning Society

\author{
Journal of Transport Literature \\ Vol. 8, n. 3, pp. 229-249, Jul. 2014 \\ Research Directory
}

JTL | RELIT

www.transport-literature.org ISSN 2238-1031

\title{
Análise do Aeroporto Salgado Filho como polo gerador de viagens
}

[Analysis of the Salgado Filho Airport as a trip generator center]

\author{
Lenise Grando Goldner, Aline de Melo Nascimento, Ilce Marilia Dantas Pinto* \\ Santa Catarina Federal University - Brazil, Santa Catarina Federal University - Brazil, Bahia Federal University - Brazil
}

Submitted 6 May 2013; received in revised form 30 Sep 2013; accepted 1 Nov 2013

\begin{abstract}
Resumo
Os aeroportos são importantes polos geradores de viagens e, portanto atraem um grande número de viagens por seus acessos terrestres, que quando não estão bem dimensionados produzem atrasos e congestionamentos, implicando no aumento do tempo da viagem como um todo. Neste trabalho buscou-se analisar as viagens terrestres de entrada e saída do aeroporto Salgado Filho em Porto Alegre, realizando contagens de tráfego no dia de semana de maior movimento de um mês típico. A partir dos dados obtidos elaboraram-se taxas de geração de viagens relacionando o número de viagens com o número de passageiros embarcando e desembarcando, o número de aeronaves pousando e decolando e a área construída dos seus terminais. Como produto principal obteve-se uma taxa diária de 1,73 viagens terrestres por passageiro que utiliza o aeroporto. Os resultados desse trabalho poderão contribuir no planejamento de outros aeroportos com características similares, ou mesmo na ampliação e melhoramentos no próprio aeroporto estudado.
\end{abstract}

Palavras-Chave: aeroporto, polo gerador de viagens, modelos de geração de viagens.

\begin{abstract}
Airports are important Trip Generator Centers attracting a high number of trips on their land access ways. Inadequate dimensioning of access routes leads to delays and congestion increasing trip times for all. This study analyzed land trips at the entrance and exit of the Salgado Filho airport in Porto Alegre on the weekday with the most intense traffic flows in a typical month. The data gathered was used to calculate trip generation rates relating the number of trips to the number of arriving and departing passengers, the number of aircraft taking off and landing and the area of the airport terminal buildings.t. The main study output was the daily trip generating rate - 1.73 land trips per passenger using that airport. The findings may help in the planning of other airports with similar characteristics, or even the expansion and improvements at the airport studied.
\end{abstract}

Key words: airport, trip generator center, trip generation models.

*Email: ilce_marilia@hotmail.com.

\section{Recommended Citation}

Goldner, L. G., Nascimento, A. M. and Pinto, I. M. D. (2014) Análise do Aeroporto Salgado Filho como polo gerador de viagens. Journal of Transport Literature, vol. 8, n. 3, pp. 229-249.

- JTL/RELIT is a fully electronic, peer-reviewed, open access, international journal focused on emerging transport markets and published by BPTS - Brazilian Transport Planning Society. Website www.transport-literature.org. ISSN 2238-1031.

This paper is downloadable at www.transport-literature.org/open-access. 


\section{Introdução}

Os aeroportos são considerados um dos principais Polos Geradores de Viagens (PGVs) existentes em áreas urbanas e como tal atraem um grande número de viagens terrestres, realizadas não somente pelos passageiros que desejam embarcar ou desembarcar no aeroporto, mas também por acompanhantes, funcionários das companhias aéreas e da administração, visitantes etc. Como consequência estas viagens impactam o sistema viário do entorno, produzindo problemas de fluidez e segurança no tráfego e necessitando de um grande número de vagas de estacionamento de automóveis.

Levando-se em consideração que as vias de acesso aos aeroportos normalmente fazem parte da malha viária da cidade, sendo, portanto, utilizadas por outros usuários, e que a maioria das cidades brasileiras possuem problemas de congestionamento, o volume de tráfego gerado pode assumir valores significativos. Observam-se em muitos casos as vias operando em níveis de serviço desfavoráveis, produzindo um aumento do tempo da viagem de acesso ou egresso ao aeroporto.

Portanto, para um desempenho satisfatório da infraestrutura aeroportuária, é necessário um bom planejamento dos acessos terrestres aos aeroportos. Trata-se de um problema que necessita ser enfrentado pelo órgão gestor da cidade e pela própria administração do aeroporto.

No Brasil temos o agravante de que as viagens de acesso e egresso aos aeroportos são feitas principalmente utilizando o modo automóvel, como comprovam algumas pesquisas realizadas sobre o padrão de viagens em vários aeroportos do país, que serão explicitadas na revisão bibliográfica a seguir. No exterior tem-se o atenuante de existirem opções de transporte como o trem, o metrô e mesmo o próprio ônibus (shutlle service), que servem os aeroportos e são meios alternativos de deslocamento.

Sendo assim, torna-se de significativa importância a quantificação das viagens terrestres aos aeroportos, como auxílio ao planejador de transportes para o dimensionamento adequado do sistema viário de acesso aos mesmos. A adequação das vias à demanda resultará em um 
aumento da acessibilidade e consequentemente uma diminuição do tempo de viagem, contribuindo para a melhoria da atratividade do transporte aéreo e do respectivo aeroporto.

Este artigo tem como objetivo analisar as viagens terrestres ao aeroporto Salgado Filho em Porto Alegre RS, de modo a conhecer o padrão de suas viagens nas vias de acesso e a partir dessa informação, elaborar taxas de geração de viagens com o fim de propor modelos e parâmetros para o dimensionamento das entradas e saídas deste aeroporto, de modo a oferecer ao usuário níveis de serviço aceitáveis e garantir a fluidez do tráfego na sua área de influência.

A metodologia utilizada nesse artigo tomou por base a coleta e análise de dados mensais de movimento de passageiros e aeronaves que foram fornecidos pela administração da INFRAERO para os anos de 2009, 2010 e 2011 (para definição do dia de projeto) e de uma pesquisa volumétrica classificada de veículos realizada com o objetivo de analisar as viagens terrestres de entrada e saída do aeroporto Salgado Filho em Porto Alegre. A partir desses dados, elaboraram-se então, taxas de geração de viagens relacionando o número de viagens com o número de passageiros embarcando e desembarcando, o número de aeronaves pousando e decolando e a área construída dos seus terminais.

Espera-se que os resultados obtidos possam ser úteis no planejamento de outros aeroportos com características similares, ou mesmo na ampliação e melhoramentos no próprio aeroporto estudado.

É necessário ressaltar a importância de outros tipos de estudos, que incentivem a mudança na distribuição modal das viagens, estimulando a implantação e o uso de outros modos de transporte além do automóvel, como já está sendo feito em países mais desenvolvidos.

Este trabalho é constituído de uma revisão bibliográfica, contida na Seção 1; informações sobre o aeroporto Salgado Filho, na Seção 2; a descrição do procedimento proposto para o desenvolvimento da pesquisa, descrito na Seção 3; os resultados da pesquisa, na Seção 4 e a seção de conclusões seguida das referências bibliográficas. 


\section{Revisão bibliográfica}

Existem vários estudos sobre o acesso terrestre aos aeroportos, especialmente os desenvolvidos no exterior e poucos os estudos realizados no Brasil sobre o tema. Sobre estes últimos será dada ênfase neste artigo.

Shapiro e Katzman (1998) publicaram um guia para planejamento dos acessos terrestres aos aeroportos para vários modos de transporte. A publicação desse estudo foi resultado do reconhecimento de que havia pouca orientação disponível para os operadores aeroportuários e as organizações de planejamento metropolitanas para a implantação de sistemas intermodais de transporte para aeroportos nos Estados Unidos.

Ruhl e Trnavskis (1998) realizaram um amplo estudo para obter dados atualizados para elaboração de modelos de geração de viagens para aeroportos. As informações obtidas foram derivadas de aeroportos americanos durante o verão de 1996. Este trabalho também analisou dados obtidos do Plano do Sistema de Aviação da Califórnia, de três planos diretores de aeroportos existentes e de estudos individuais sobre o acesso terrestre a aeroportos, além de contagens de tráfego. A compilação dos mesmos teve como objetivo analisar a geração de viagens e a divisão modal para 39 aeroportos de serviço aéreo comercial.

Em 2008, a Airport Cooperative Research Program publicou um relatório sobre o acesso terrestre aos principais aeroportos pelo transporte público, escrito por Coogan em associação com Jacobs e MarketSense Consultoria (COOGAN, 2008). Esse estudo apresentou uma vasta gama de informação sobre os serviços de transporte público em aeroportos, tanto nos Estados Unidos como em outros países do mundo.

Gosling (2008) escreveu uma síntese sobre os modelos de escolha do modo de transporte para o acesso terrestre aos aeroportos, com uma revisão abrangente da literatura neste campo.

Kouwenhoven (2008) publicou um artigo com o objetivo de dar uma visão geral sobre o papel da acessibilidade como um fator na escolha dos aeroportos realizada pelos passageiros e principalmente, para verificar se a mudança da acessibilidade de um aeroporto influenciava no volume de passageiros que o utilizavam, já que nos Estados Unidos as pessoas tem a 
possibilidade de escolher entre vários aeroportos aquele que é mais conveniente para realizar sua viagem.

Uma das publicações mais conhecida e utilizada em diferentes países é o estudo do Institute of Transportation Engineers - ITE (2008) - denominada “Trip Generation”. Nessa edição, foram apresentados vários modelos para aeroportos comerciais e da aviação geral, e os modelos para aeroportos comerciais relacionavam o número de viagens de acesso e egresso, tanto para um dia de semana típico como no horário de pico das vias adjacentes e dos aeroportos, indicando como variáveis representativas dessas viagens: o número de empregados do aeroporto, o número médio de voos por dia e o número de voos comerciais por dia.

No Brasil, Goldner e Andrade (2003, 2004) e Goldner et al. (2004, 2005a, 2005b) estudaram as características das viagens terrestres aos aeroportos Hercílio Luz em Florianópolis e Salgado Filho em Porto Alegre, elaboraram taxas para o dimensionamento do estacionamento e modelos de escolha modal utilizando-se o modelo Logit Multinomial, além de entrevistas com a técnica de preferência declarada para definição do melhor valor de tarifa de estacionamento para estes aeroportos.

A Agência Nacional de Aviação Civil - ANAC, publicou um relatório, elaborado pela Superintendência de Infraestrutura Aeroportuária - SIE, por intermédio da Gerência de Estudos Aeroportuários - GEAR, onde foram disponibilizadas as estatísticas sobre a movimentação de passageiros, aeronaves, e do agregado de carga e mala postal dos principais aeroportos brasileiros no período de 2005-2007 (ANAC, 2009).

Monteiro (2010) realizou um trabalho sobre a análise dos acessos terrestres em cenários futuros e o impacto a ser gerado pelo novo terminal aeroportuário de Florianópolis - SC, em implantação e Goldner e Monteiro (2011) estudaram a taxa de geração de viagens para o aeroporto Hercílio Luz em Florianópolis- SC.

Alves e Strambi (2011) estudaram a escolha de modo no acesso terrestre ao aeroporto Internacional André Franco Montoro, em São Paulo, utilizando uma pesquisa de preferência declarada para identificar a importância dos fatores que afetam a escolha do modo, principalmente a variável confiabilidade no tempo de viagem. Os resultados foram utilizados 
para a estimação de modelos de escolha discreta do modo de transporte no acesso terrestre ao aeroporto. Foi observado que a importância da confiabilidade do tempo de viagem é maior do que a atribuída ao tempo esperado de viagem e não foi afetada por variações sistemáticas.

Teixeira et al (2012) publicaram um artigo sobre um estudo no aeroporto de Viracopos onde foi utilizado a aplicação da Análise Multicritério à decisão na escolha de opções de estacionamento. Esse modelo leva em consideração o ponto de vista e os interesses dos diversos atores envolvidos, englobando os usuários do aeroporto (passageiros, visitantes, taxistas, empresas de transportes coletivos e de cargas, funcionários e fornecedores), a Empresa Brasileira de Infraestrutura Aeroportuária - INFRAERO e as companhias aéreas. Além disso, esse modelo possibilitou propor e avaliar três alternativas viáveis para solucionar o problema de estacionamento desse aeroporto, e ainda analisar a opção que melhor satisfez tecnicamente os atores envolvidos.

\section{O aeroporto Salgado Filho}

O aeroporto Salgado Filho, localizado em Porto Alegre - RS, Brasil, possui atualmente dois terminais. As obras do novo terminal (terminal 1) foram concluídas em 2001, e este está localizado na Avenida Severo Dulius. O antigo terminal (terminal 2) se encontra na Avenida dos Estados. O aeroporto está localizado a $10 \mathrm{~km}$ do centro de Porto Alegre por vias terrestres, tendo duas vias principais de acesso, em função da localização dos terminais.

De acordo com a INFRAERO (2012), o sítio aeroportuário de Porto Alegre possui $3.805 .810,04 \mathrm{~m}^{2}$, onde $37.500 \mathrm{~m}^{2}$ correspondem à área total construída do novo terminal e $14.500 \mathrm{~m}^{2}$ área total construída do terminal antigo. Ele possui também um edifício garagem de oito pavimentos, com $44.000 \mathrm{~m}^{2}$ de área construída e com capacidade para 1.440 vagas, além de três outros estacionamentos horizontais descobertos. A Figura 1 a seguir apresenta uma vista aérea do aeroporto Salgado Filho. 


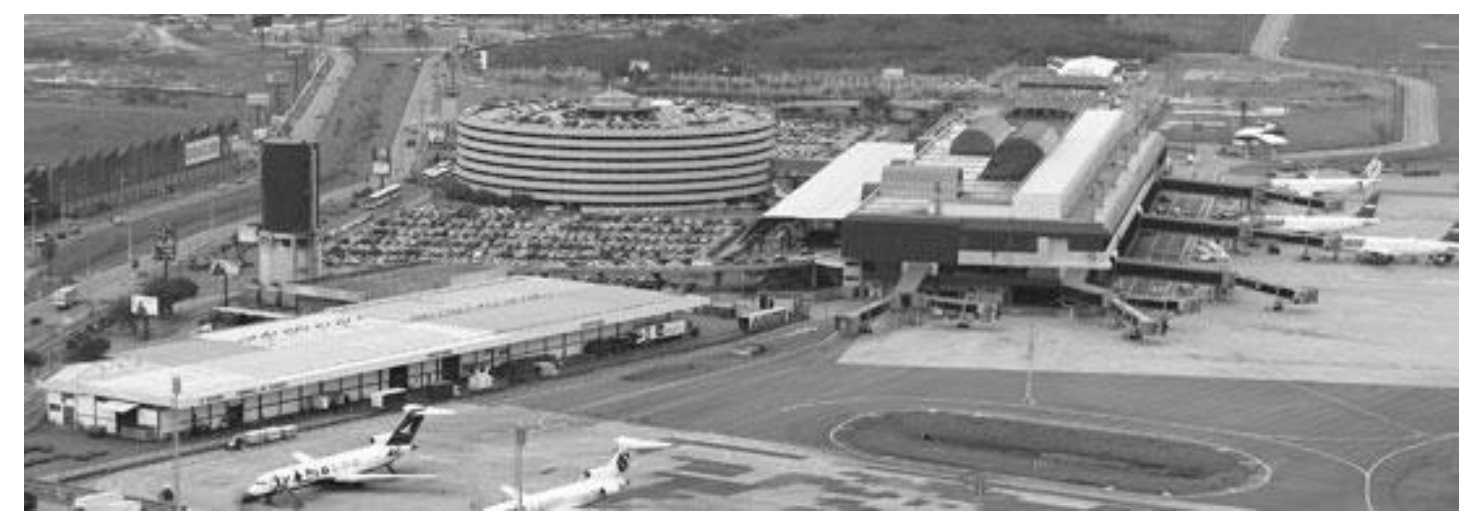

Figura 1 - Vista aérea do aeroporto Salgado Filho

Fonte: INFRAERO (2012)

O aeroporto Salgado Filho se situou em sexto lugar na classificação dos maiores aeroportos brasileiros em relação ao mercado doméstico e internacional, considerando o embarque e desembarque no período de 2005 à 2007 (ANAC, 2009). No período de 2009 e 2011 houve um aumento de aproximadamente $25 \%$ de voos, entre os voos domésticos e internacionais, o que também significou em um aumento de mais de 2 milhões de passageiros. Entre o ano de 2009 e 2010, o número de voos domésticos subiu de 69.322 para 88.522, representando um aumento de $27 \%$. Nesse mesmo intervalo, o crescimento de voos internacionais foi respectivamente de 9.782 para 11.061 , significando um aumento de $16 \%$.

Segundo a INFRAERO (2012), a capacidade anual do terminal 1 é de 8 milhões de passageiros/ano, enquanto a do terminal 2 é de 2,5 milhões de passageiros/ano, totalizando em 10,5 milhões de passageiros/ano. Em 2011, o aeroporto Salgado Filho atendeu um total de 7.834.312 passageiros, com uma média de 652.859 passageiros ao mês. Portanto a capacidade do aeroporto não está esgotada. O terminal de passageiros opera 24 horas por dia. A pista opera entre 5:00 horas da manhã à 1:00 da manhã do dia seguinte. 


\section{Procedimento proposto}

Analisando-se os dados mensais de movimento de passageiros e aeronaves que foram fornecidos pela administração da INFRAERO para os anos de 2009, 2010 e 2011, concluiu-se que o mês que mais se aproximava da média era o mês de maio, por isso esse foi o mês escolhido para fazer a contagem de tráfego.

Para a escolha do dia da semana representativo para contagem de tráfego avaliou-se o movimento de aeronaves e passageiros no período de 16 a 22 de maio, considerada uma semana típica. Concluiu-se que a pesquisa de contagem de tráfego seria realizada numa sextafeira, pois o dia pico durante a semana típica se apresentou nesse dia.

Em função de questões organizacionais da equipe de campo para o trabalho da coleta de dados, a pesquisa foi programada para ser realizada na última semana do mês de maio, numa sexta-feira. Entretanto, devido a uma festa que aconteceu em frente ao aeroporto no dia programado para a realização da pesquisa, foi decidido adiar a mesma por uma semana para não haver interferências na contagem, pois os participantes do evento poderiam usar o estacionamento do aeroporto e com isso alterar significativamente o volume de tráfego. Portanto, a pesquisa foi realizada no dia 01 de junho, mesmo dia da semana anteriormente previsto.

Os postos de contagem de tráfego foram agrupados em função da localização dos dois terminais (terminal novo - terminal 1 e terminal antigo - terminal 2) e podem ser observados nas Figuras 2 e 3. Os movimentos de entrada e saída de veículos que foram contados na posição dos postos de contagem, para os terminais 1 e 2 , os quais estão representados nestas figuras. As contagens volumétricas foram classificadas por tipo de veículo e o período de contagem foi entre 5:00 horas da manhã da sexta-feira até 1:00 hora da madrugada de sábado, o que correspondeu ao período em que a pista do aeroporto estava operando. 


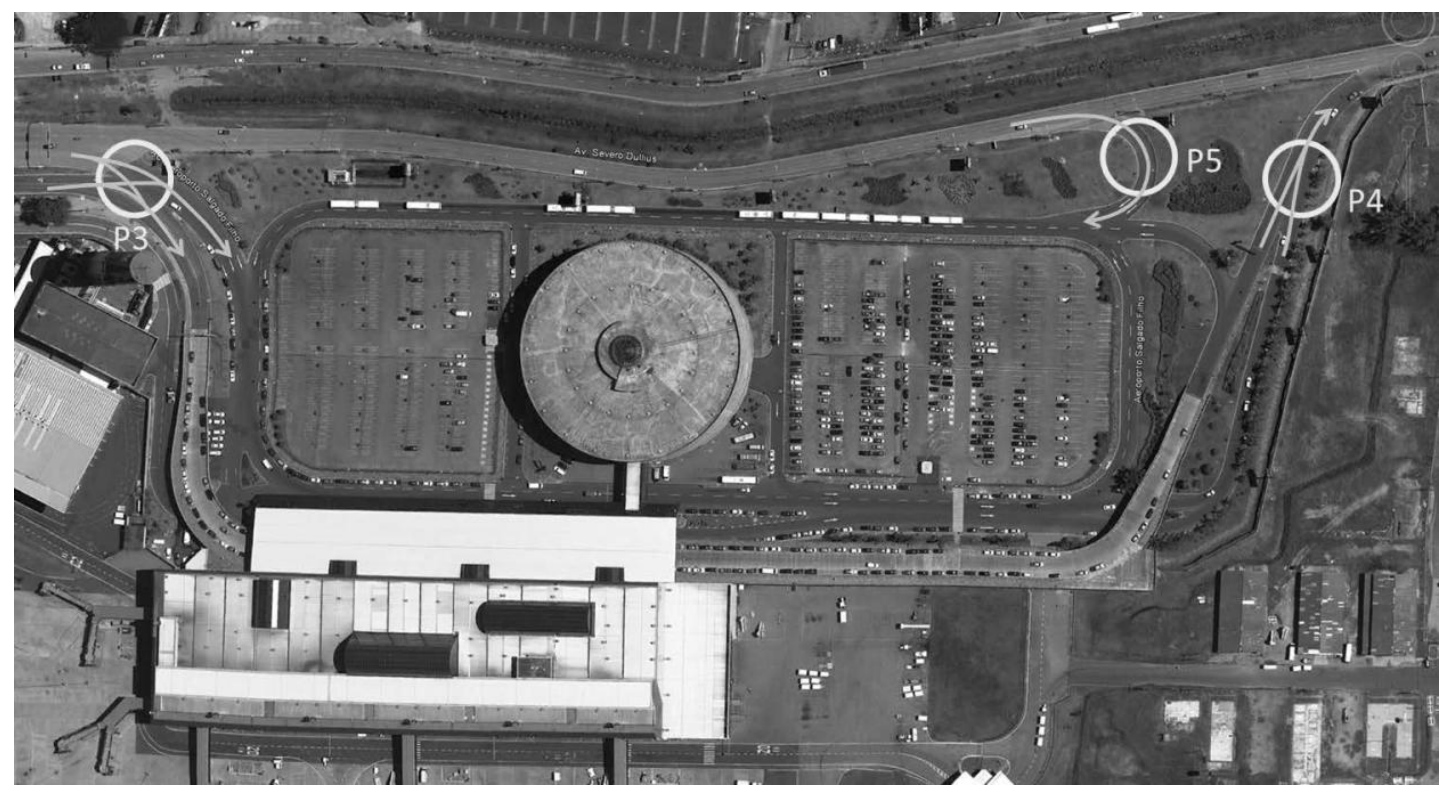

Figura 2 - Terminal novo (terminal 1) - Pontos de contagem Fonte: Google Earth adaptado

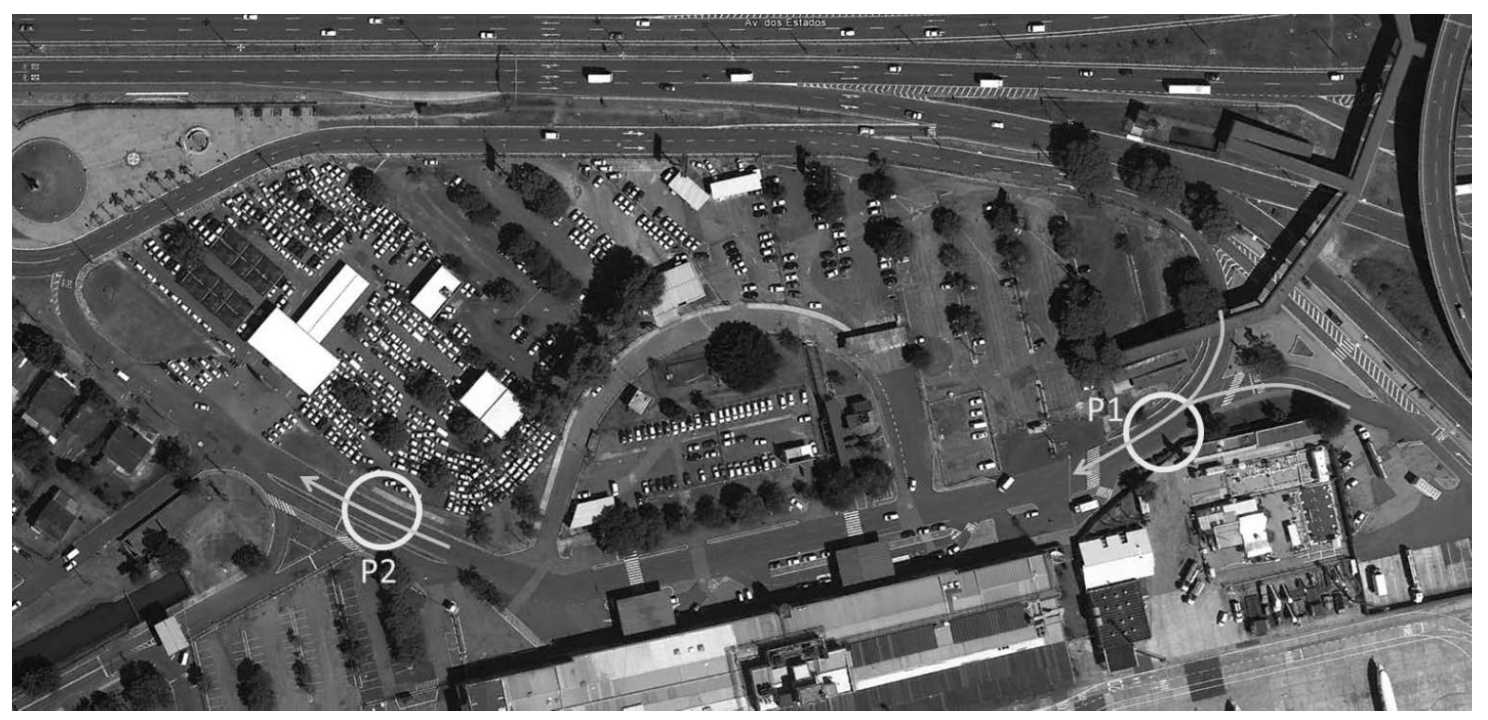

Figura 3 - Terminal antigo (terminal 2) - Pontos de contagem

Fonte: Google Earth adaptado

Durante o período de contagem, a movimentação no terminal novo e antigo foi de 42.250 veículos, dentro dos quais 20.701 veículos entrando nos terminais e 21.549 veículos saindo dos terminais. No horário de pico, houve 1.583 veículos entrando nos dois terminais e 1.661 veículos saindo dos mesmos, totalizando 3.244 veículos. 


\section{Resultados obtidos}

\subsection{Percentagem de pico horário, distribuição modal e distribuição direcional.}

De acordo com os dados coletados na pesquisa de campo, foi possível agrupá-los em intervalos horários. Portanto, nas Figuras 4, 5 e 6 a seguir, observam-se os movimentos de veículos por hora, ao longo do dia de contagem, apresentados em forma de percentagem. A percentagem que corresponde à hora de pico denomina-se Percentagem de Pico Horário PPH. Nas citadas figuras apresentam-se os histogramas distribuídos para a hora cheia mais 45 minutos, pois esses intervalos coincidem com a hora-pico.

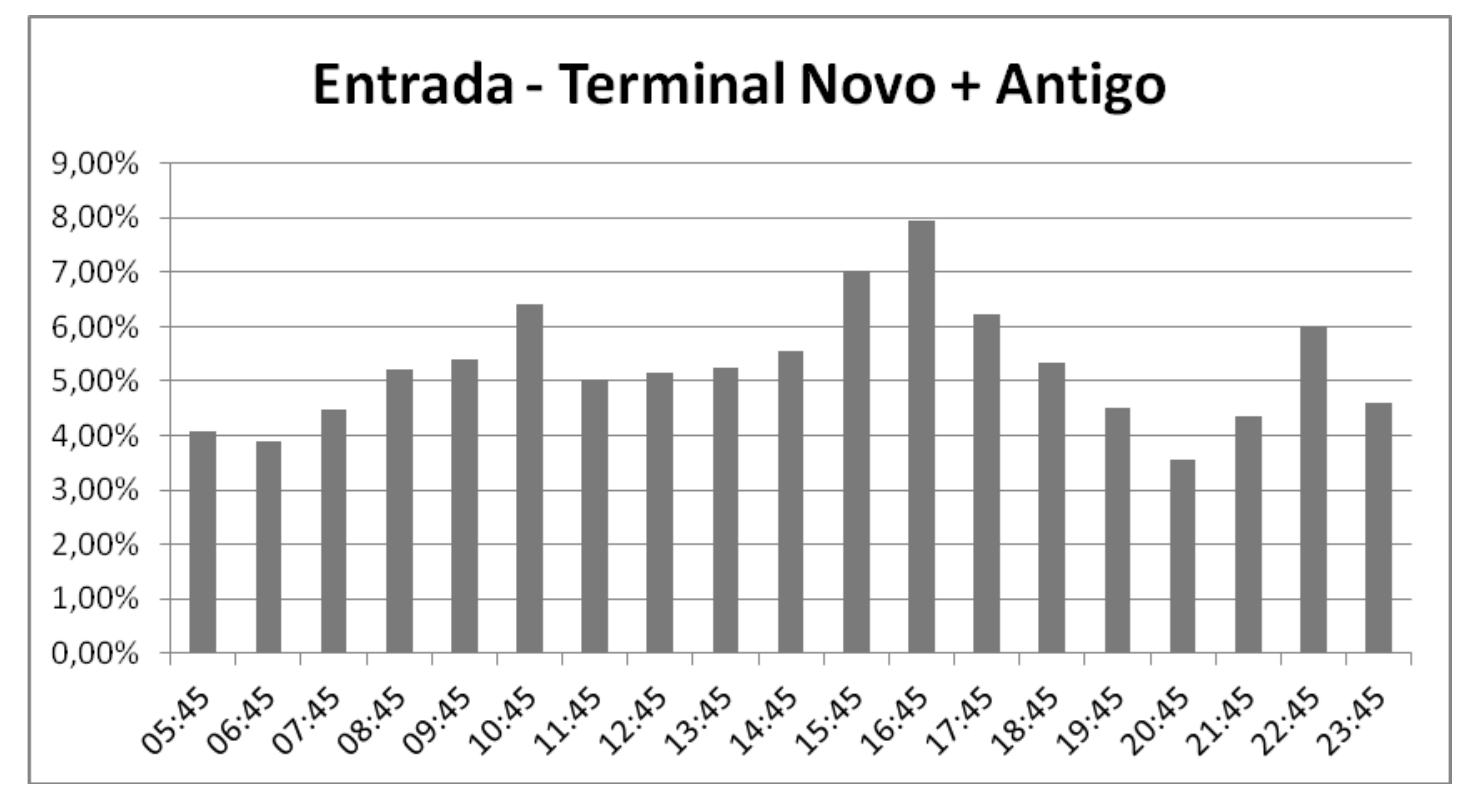

\section{Figura 4 - Percentagem horária para os movimentos de veículos entrando no dia da contagem}

De acordo com a Figura 4, a percentagem de pico horário (PPH) para o movimento de entrada do aeroporto é de $7,94 \%$ e a hora pico acontece entre $16 \mathrm{~h} 45 \mathrm{~min}$ e $17 \mathrm{~h} 45 \mathrm{~min}$. 


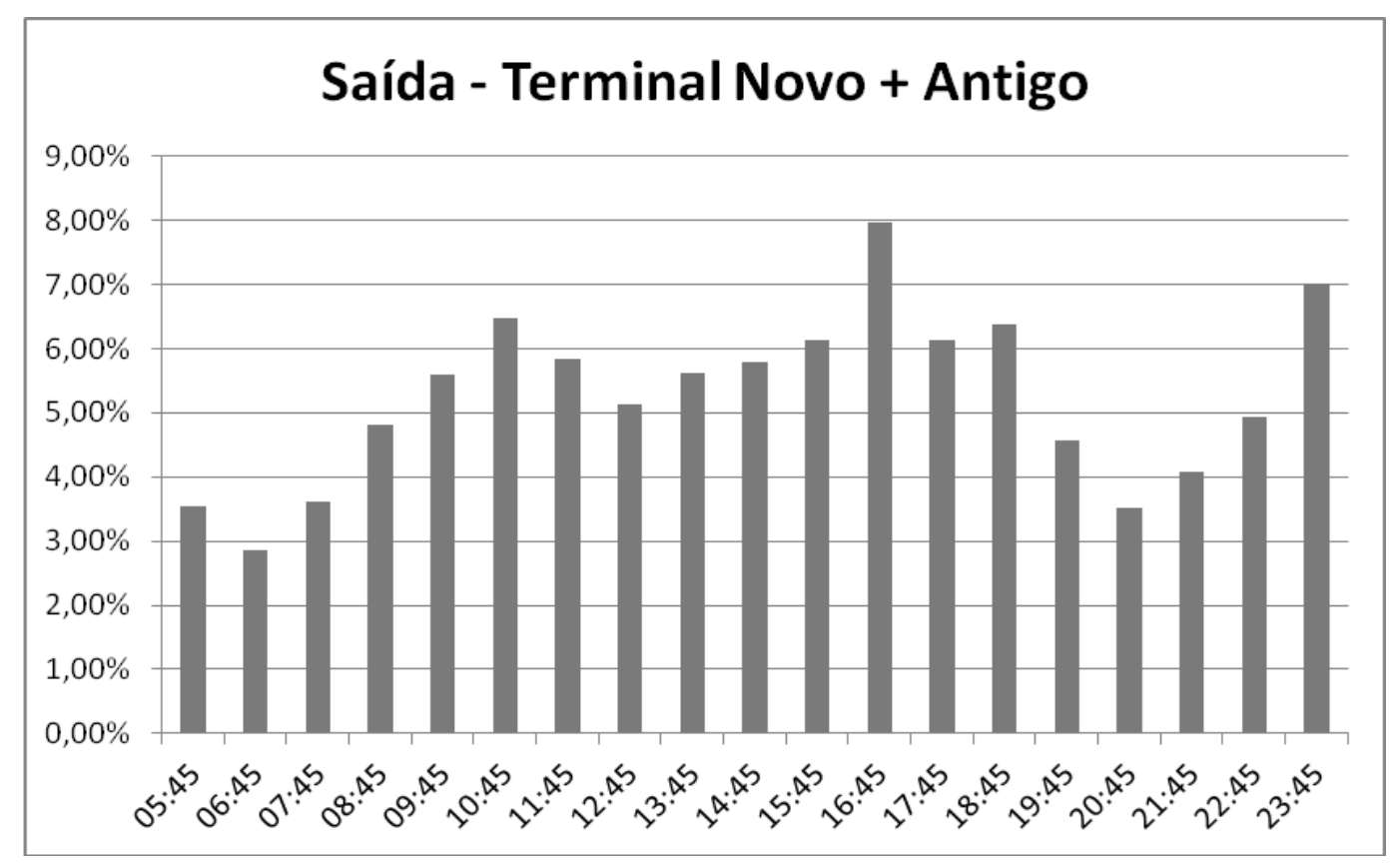

Figura 5 - Percentagem horária para os movimentos de veículos saindo no dia da contagem

Para o movimento de saída do aeroporto, o PPH é de 7,97\%, e acontece também no horário de 16h45min às $17 \mathrm{~h} 45 \mathrm{~min}$.

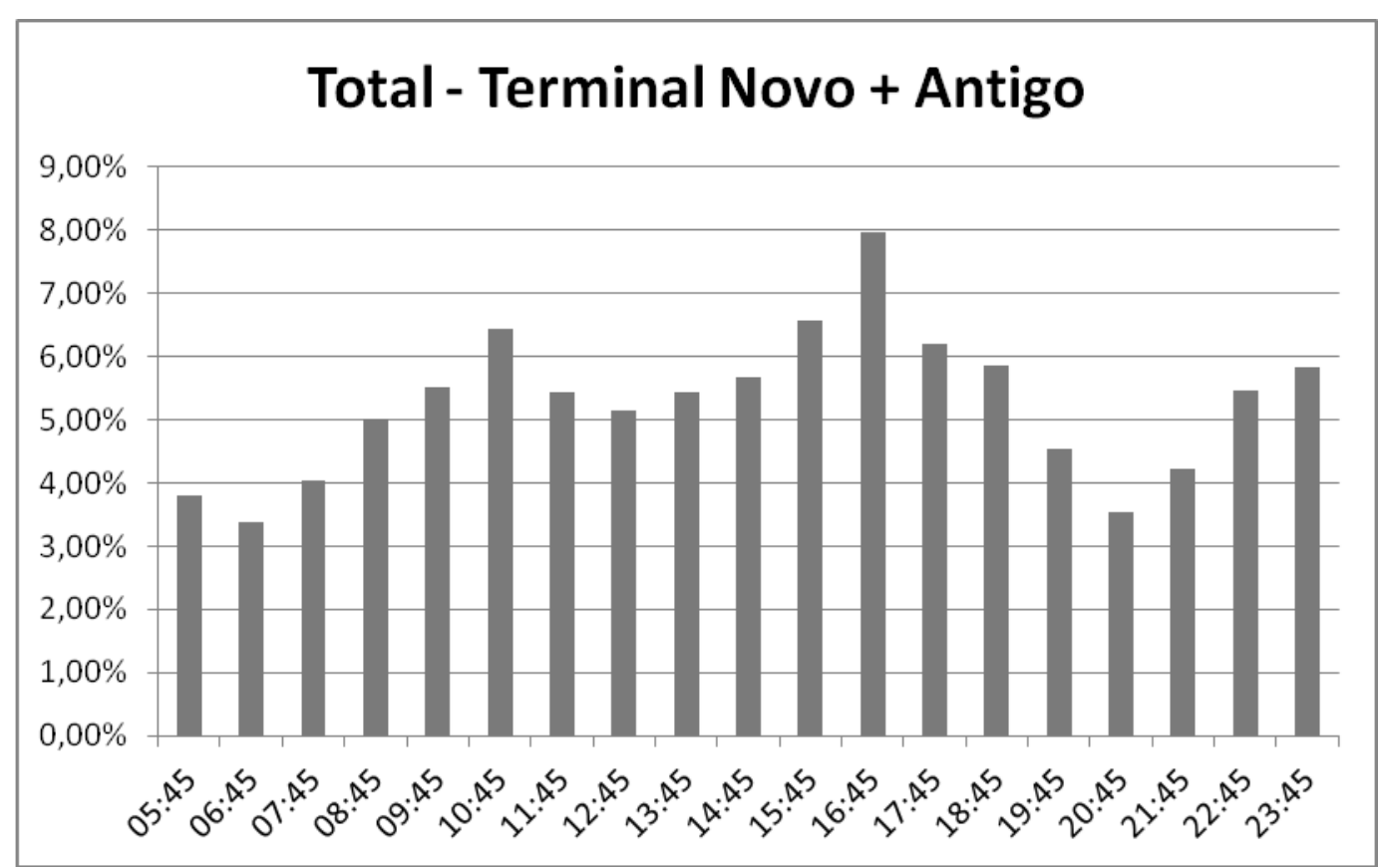

Figura 6 - Percentagem horária para os movimentos de veículos totais no dia da contagem 
Totalizando os fluxos de entrada e saída, observa-se na Figura 6 que o PPH é de 7,95\% e acontece no horário de $16 \mathrm{~h} 45 \mathrm{~min}$ a $17 \mathrm{~h} 45 \mathrm{~min}$.

Como as contagens de tráfego nas entradas e saídas do aeroporto foram classificadas, pode-se obter a distribuição modal, apresentada nas Tabelas 1, 2 e 3, considerando-se os tipos de veículos para o total do aeroporto, isto é, a soma do movimento do terminal novo mais a do terminal antigo.

Tabela 1 - Distribuição Modal - Entrada nos terminais

\begin{tabular}{|l|c|c|c|c|c|c|c|c|}
\hline & \multicolumn{7}{|c|}{ Terminal Antigo + Novo - Tráfego de Entrada } \\
\cline { 2 - 9 } & Carro & Ônibus & Moto & Caminhão & Lot/Van & Táxi & Outros & Total \\
\hline \multirow{2}{*}{$16: 45-17: 45$} & 925 & 47 & 46 & 5 & 87 & 471 & 2 & 1583 \\
\cline { 2 - 9 } & $58,43 \%$ & $2,97 \%$ & $2,91 \%$ & $0,32 \%$ & $5,50 \%$ & $29,75 \%$ & $0,13 \%$ & $100 \%$ \\
\hline \multirow{2}{*}{ Dia Inteiro } & 11714 & 695 & 465 & 147 & 1026 & 6627 & 27 & 20701 \\
\cline { 2 - 9 } & $56,59 \%$ & $3,36 \%$ & $2,25 \%$ & $0,71 \%$ & $4,96 \%$ & $32,01 \%$ & $0,13 \%$ & $100 \%$ \\
\hline
\end{tabular}

Tabela 2 - Distribuição Modal - Saída nos terminais

\begin{tabular}{|l|c|c|c|c|c|c|c|c|}
\hline & \multicolumn{8}{|c|}{ Terminal Antigo + Novo - Tráfego de Saída } \\
\cline { 2 - 9 } & Carro & Onibus & Moto & Caminhão & Lot/Van & Táxi & Outros & Total \\
\hline \multirow{2}{*}{$16: 45-17: 45$} & 960 & 40 & 45 & 14 & 62 & 538 & 2 & 1661 \\
\cline { 2 - 9 } & $57,80 \%$ & $2,41 \%$ & $2,71 \%$ & $0,84 \%$ & $3,73 \%$ & $32,39 \%$ & $0,12 \%$ & $100 \%$ \\
\hline \multirow{2}{*}{ Dia Inteiro } & 12178 & 735 & 584 & 156 & 962 & 6906 & 28 & 21549 \\
\cline { 2 - 9 } & $56,51 \%$ & $3,41 \%$ & $2,71 \%$ & $0,72 \%$ & $4,46 \%$ & $32,05 \%$ & $0,13 \%$ & $100 \%$ \\
\hline
\end{tabular}

Tabela 3 - Distribuição Modal - Entrada + Saída - terminal novo + antigo

\begin{tabular}{|l|c|c|c|c|c|c|c|c|}
\hline & \multicolumn{7}{|c|}{ Total - Tráfego de Entrada + Saída } \\
\cline { 2 - 9 } & Carro & Onnibus & Moto & Caminhão & Lot/Van & Táxi & Outros & Total \\
\hline \multirow{2}{*}{$16: 45-17: 45$} & 1885 & 87 & 91 & 19 & 149 & 1009 & 4 & 3244 \\
\cline { 2 - 9 } & $58,11 \%$ & $2,68 \%$ & $2,81 \%$ & $0,59 \%$ & $4,59 \%$ & $31,10 \%$ & $0,12 \%$ & $100 \%$ \\
\hline \multirow{2}{*}{ Dia Inteiro } & 23892 & 1430 & 1049 & 303 & 1988 & 13533 & 55 & 42250 \\
\cline { 2 - 9 } & $56,55 \%$ & $3,38 \%$ & $2,48 \%$ & $0,72 \%$ & $4,71 \%$ & $32,03 \%$ & $0,13 \%$ & $100 \%$ \\
\hline
\end{tabular}

É possível observar na Tabela 3 que o principal meio de transporte utilizado no aeroporto é o automóvel, pois $56,55 \%$ dos veículos que trafegaram durante o período da contagem constituíram-se de carros particulares e 32,03\% foram táxis. Ainda em relação à escolha modal $4,71 \%$ foram lotações e vans, $3,38 \%$ e 2,48\% ônibus e motos, respectivamente. Por último, com $0,72 \%$ encontram-se os caminhões. 
Como as contagens de tráfego foram realizadas separadamente para movimento de entrada e saída pode-se obter a distribuição direcional dos fluxos, para o dia inteiro (Tabela 4) e para a hora de pico (Tabela 5).

Tabela 4 - Distribuição direcional - Terminal Novo + Antigo - dia inteiro

\begin{tabular}{|c|c|c|c|}
\hline \multirow{2}{*}{ Distribuição Direcional do Tráfego } & \multicolumn{3}{|c|}{ Terminal Antigo + Novo } \\
\cline { 2 - 4 } & Entrada & Saída & Total \\
\hline Somatória de veículos & 20.701 & 21.549 & 42.250 \\
\hline \% em relação ao total geral & $49,00 \%$ & $51,00 \%$ & $100,00 \%$ \\
\hline
\end{tabular}

Como se pode observar na Tabela 4, considerando o somatório dos dois terminais de passageiros e a distribuição direcional diária, existe uma pequena tendência dos movimentos de saída (51\%) em relação ao movimento de entrada (49\%). Para melhor entendimento desse comportamento, alguns fatores podem ser considerados: os veículos entraram nos terminais no dia anterior ou dias anteriores a realização da contagem e ficaram no estacionamento até o retorno da viagem ou estes veículos entraram antes do período da contagem e saíram no horário da contagem, pois a contagem de tráfego foi realizada durante o período de operação da pista, das 5 horas de sexta-feira até 1 h de sábado, mas os terminais operam 24 horas. No horário de pico também acontece o mesmo fenômeno citado no parágrafo anterior: 48,80\% dos veículos entram no terminal e 51,20\% saem do terminal, conforme se observa na Tabela 5 .

\section{Tabela 5 - Distribuição direcional - Terminal Novo e Antigo - Horário Pico}

\begin{tabular}{|c|c|c|c|}
\hline \multirow{2}{*}{ Distribuição Direcional do Tráfego } & \multicolumn{3}{|c|}{ Terminal Novo + Antigo } \\
\cline { 2 - 4 } & Entrada & Saída & Total \\
\hline Somatória de veículos no horário pico & 1.583 & 1.661 & 3.244 \\
\hline \% em relação ao total geral & $48,80 \%$ & $51,20 \%$ & $100,00 \%$ \\
\hline
\end{tabular}

Outro aspecto que deve ser destacado é que uma existe ligação viária entre o terminal novo e o antigo. Dessa forma, pode acontecer que a entrada do veículo seja realizada pelo terminal novo e a saída pelo terminal antigo. Durante a pesquisa observou-se que esse procedimento é comum entre os táxis. 


\subsection{Modelos de geração de viagens}

As Tabelas de 6, 7, 8 e 9 apresentam as taxas de geração de viagens estimadas para esse estudo de caso, relacionando-se o volume de veículos (entrando, saindo ou o total) com o número de passageiros no período (embarcando + desembarcando) e o número de aeronaves (pousos + decolagens).

As Tabelas 6 e 7, a seguir, mostram as taxas de geração de viagens horárias, relacionando-se o volume de veículos (entrando, saindo e total) com o número de passageiros (embarcando, desembarcando e total) no dia inteiro e no horário de pico.

Tabela 6 - Taxas de geração de viagem por passageiro - Dia inteiro

\begin{tabular}{|c|c|c|c|}
\hline \multirow{4}{*}{ Terminal Novo } & Viagens Entrando & Passageiros Embarcando & Viagens/pax \\
\cline { 2 - 4 } & 15.911 & 8.865 & 1,79 \\
\cline { 2 - 4 } & Viagens Saindo & Passageiros Desembarcando & Viagens/pax \\
\cline { 2 - 4 } & 13.251 & 8.983 & 1,48 \\
\cline { 2 - 4 } & Viagens Total & Passageiros Total & Viagens/pax \\
\cline { 2 - 4 } & 29.162 & 17.848 & 1,63 \\
\cline { 2 - 4 } & Viagens Entrando & Passageiros Embarcando & Viagens/pax \\
\cline { 2 - 4 } & 4.790 & 3.440 & 1,39 \\
\cline { 2 - 4 } & Viagens Saindo & Passageiros Desembarcando & Viagens/pax \\
\cline { 2 - 4 } & 8.298 & 3.179 & 2,61 \\
\cline { 2 - 4 } & Viagens Total & Passageiros Total & Viagens/pax \\
\cline { 2 - 4 } & 13.088 & 6.619 & 1,98 \\
\hline \multirow{5}{*}{+ Antigo } & Viagens Entrando & Passageiros Embarcando & Viagens/pax \\
\cline { 2 - 4 } & 20.701 & 12.305 & 1,68 \\
\cline { 2 - 4 } & Viagens Saindo & Passageiros Desembarcando & Viagens/pax \\
\cline { 2 - 4 } & 21.549 & 12.162 & 1,77 \\
\cline { 2 - 4 } & Viagens Total & Passageiros Total & Viagens/pax \\
\cline { 2 - 4 } & 42.250 & 24.467 & 1,73 \\
\hline
\end{tabular}


Tabela 7 - Taxas de geração de viagem por passageiro - Hora Pico

\begin{tabular}{|c|c|c|c|c|}
\hline \multirow{18}{*}{ Hora Pico } & \multirow{6}{*}{ Terminal Novo } & Viagens Entrando & Passageiros Embarcando & Viagens/pax \\
\hline & & 1.255 & 827 & 1,52 \\
\hline & & Viagens Saindo & Passageiros Desembarcando & Viagens/pax \\
\hline & & 965 & 681 & 1,42 \\
\hline & & Viagens Total & Passageiros Total & Viagens/pax \\
\hline & & 2.220 & 1.508 & 1,47 \\
\hline & \multirow{6}{*}{ Terminal Antigo } & Viagens Entrando & Passageiros Embarcando & Viagens/pax \\
\hline & & 328 & 228 & 1,44 \\
\hline & & Viagens Saindo & Passageiros Desembarcando & Viagens/pax \\
\hline & & 696 & 217 & 3,21 \\
\hline & & Viagens Total & Passageiros Total & Viagens/pax \\
\hline & & 1.024 & 445 & 2,30 \\
\hline & \multirow{6}{*}{$\begin{array}{l}\text { Terminal Novo } \\
+ \text { Antigo }\end{array}$} & Viagens Entrando & Passageiros Embarcando & Viagens/pax \\
\hline & & 1.583 & 1.055 & 1,50 \\
\hline & & Viagens Saindo & Passageiros Desembarcando & Viagens/pax \\
\hline & & 1.661 & 898 & 1,85 \\
\hline & & Viagens Total & Passageiros Total & Viagens/pax \\
\hline & & 3.244 & 1.953 & 1,66 \\
\hline
\end{tabular}

Considerando-se o movimento do dia inteiro, conforme se observa na Tabela 6, a taxa final obtida foi de 1,73 viagens por passageiro. As taxas de geração de viagens da Tabela 7 referem-se ao volume horário de veículos pelo número de passageiros que utilizaram o aeroporto na hora de pico. A taxa final encontrada foi de 1,66 viagens por passageiro. E da mesma forma que observado nas taxas diárias, tem-se que a taxa de geração de viagens para o terminal novo $(1,47)$ é menor do que a taxa para o terminal antigo $(2,30)$, devido ao maior número de viagens saindo deste último. Como já explicitado existe a possibilidade de se entrar pelo terminal 1 e sair pelo terminal 2, através da via de ligação entre eles.

As Tabelas 8 e 9, a seguir, mostram as taxas de geração de viagens horárias, relacionando-se o volume de veículos (entrando, saindo e total) com o número de aeronaves (pousos, decolagens e total). Essas taxas de geração de viagens são relativas ao dia inteiro e ao horário de pico. 
Tabela 8 - Taxas de geração de viagem por aeronave - Dia inteiro

\begin{tabular}{|c|c|c|c|}
\hline \multirow{4}{*}{ Terminal Novo } & Viagens Entrando & Aeronave Decolando & Viagens/anv \\
\cline { 2 - 4 } & 15.911 & 102 & 155,99 \\
\cline { 2 - 4 } & Viagens Saindo & Aeronave Pousando & Viagens/anv \\
\cline { 2 - 4 } & 13.251 & 104 & 127,41 \\
\cline { 2 - 4 } & Viagens Total & Aeronave Total & Viagens/anv \\
\cline { 2 - 4 } & 29.162 & 206 & 141,56 \\
\hline \multirow{5}{*}{ Terminal Antigo } & Viagens Entrando & Aeronave Decolando & Viagens/anv \\
\cline { 2 - 4 } & 4.790 & 33 & 145,15 \\
\cline { 2 - 4 } & Viagens Saindo & Aeronave Pousando & Viagens/anv \\
\cline { 2 - 4 } & 8.298 & 32 & 259,31 \\
\cline { 2 - 4 } & Viagens Total & Aeronave Total & Viagens/anv \\
\cline { 2 - 4 }$+\sqrt{5}+$ Antigo & 13.088 & 65 & 201,35 \\
\cline { 2 - 4 } & Viagens Entrando & Aeronave Decolando & Viagens/anv \\
\cline { 2 - 4 } & 20.701 & 135 & 153,34 \\
\cline { 2 - 4 } & Viagens Saindo & Aeronave Pousando & Viagens/anv \\
\cline { 2 - 4 } & 21.549 & 136 & 158,45 \\
\cline { 2 - 4 } & Viagens Total & Aeronave Total & Viagens/anv \\
\cline { 2 - 4 } & 42.250 & 271 & 155,90 \\
\hline
\end{tabular}

As taxas de geração de viagens da Tabela 8 referem-se ao volume diário de veículos pelo número de vôos que são realizados no dia da contagem. Como se pode observar, a taxa final foi de 155,90 viagens por aeronave.

Uma observação importante é que, como dito anteriormente, o horário de pico é de $16 \mathrm{~h} 45 \mathrm{~min}$ às $17 \mathrm{~h} 45 \mathrm{~min}$ e os dados de passageiros e aeronaves coletados com a administração da INFRAERO foi fornecido entre os horários de 17horas e 18horass, havendo uma pequena discrepância, já que não foi possível obter os valores exatos correspondentes a hora de pico.

As taxas descritas na Tabela 9 a seguir, representam o número total de viagens pelo número total de aeronave na hora de pico. Essa taxa foi de 180,22 viagens por aeronave. 
Tabela 9 - Taxas de geração de viagem por aeronave - Hora Pico

\begin{tabular}{|c|c|c|c|c|}
\hline \multirow{18}{*}{ Hora Pico } & \multirow{6}{*}{ Terminal Novo } & Viagens Entrando & Aeronave Decolando & Viagens/anv \\
\hline & & 1255 & 7 & 179,29 \\
\hline & & Viagens Saindo & Aeronave Pousando & Viagens/anv \\
\hline & & 965 & 7 & 137,86 \\
\hline & & Viagens Total & Aeronave Total & Viagens/anv \\
\hline & & 2220 & 14 & 158,57 \\
\hline & \multirow{6}{*}{ Terminal Antigo } & Viagens Entrando & Aeronave Decolando & Viagens/anv \\
\hline & & 328 & 2 & 164,00 \\
\hline & & Viagens Saindo & Aeronave Pousando & Viagens/anv \\
\hline & & 696 & 2 & 348,00 \\
\hline & & Viagens Total & Aeronave Total & Viagens/anv \\
\hline & & 1024 & 4 & 256,00 \\
\hline & \multirow{6}{*}{$\begin{array}{l}\text { Terminal Novo } \\
+ \text { Antigo }\end{array}$} & Viagens Entrando & Aeronave Decolando & Viagens/anv \\
\hline & & 1583 & 9 & 175,89 \\
\hline & & Viagens Saindo & Aeronave Pousando & Viagens/anv \\
\hline & & 1661 & 9 & 184,56 \\
\hline & & Viagens Total & Aeronave Total & Viagens/anv \\
\hline & & 3244 & 18 & 180,22 \\
\hline
\end{tabular}

A Tabela 10, a seguir, mostra a taxa de viagens no aeroporto Salgado Filho em relação a área total construída. Os dados referem-se ao Terminal Novo, Antigo e o Terminal de Cargas.

Tabela 10 - Área construída no aeroporto Salgado Filho

\begin{tabular}{|c|c|c|c|c|}
\hline \multirow{2}{*}{ Área construída $\left(\mathbf{m}^{\mathbf{2}}\right)$} & $\begin{array}{c}\text { Terminal } \\
\text { Novo }\end{array}$ & $\begin{array}{c}\text { Terminal } \\
\text { Velho }\end{array}$ & $\begin{array}{c}\text { Terminal } \\
\text { Velho + Novo }\end{array}$ & $\begin{array}{c}\text { Terminal } \\
\text { de carga }\end{array}$ \\
\cline { 2 - 5 } & 37.500 & 14.500 & 52.000 & 8.000 \\
\hline Viagens Entrando + Saindo & 28.967 & 12.980 & 41.949 & 303 \\
\hline Taxa (Viagens/100 $\left.\mathrm{m}^{\mathbf{2}} \mathrm{AC}\right)$ & 77,25 & 89,52 & 80,67 & 3,79 \\
\hline
\end{tabular}

Na Tabela 10, para o cálculo das viagens, descontou-se do total o número de caminhões que apareceram nas contagens, apresentando-se esse número separado e relacionando-o com a área do novo terminal de cargas a ser construído. 


\section{Conclusão}

A partir de dados fornecidos pela administração da INFRAERO do aeroporto Salgado Filho, sobre a movimentação de passageiros e aeronaves em anos anteriores ao da pesquisa, definiuse o dia de realização da contagem de tráfego, sendo este uma sexta-feira de uma semana típica, de um mês com movimento próximo a média mensal. Como se observa do exposto optou-se nesta pesquisa em trabalhar com cenários típicos, evitando o mês mais movimentado do ano. Neste aeroporto ele ocorre em Julho, época de ferias escolar e de turismo de inverno na região.

Realizaram-se as contagens volumétricas classificadas nas entradas e saídas dos dois terminais que compõe o referido aeroporto. Observou-se que existiu a predominância das viagens por automóvel, as quais representaram mais de $50 \%$ da escolha modal. O horário de pico ocorreu entre $16 \mathrm{~h} 45 \mathrm{~min}$ e $17 \mathrm{~h} 45 \mathrm{~min}$, representando 7,97\% do movimento diário.

Como resultados principais da pesquisa obtiveram-se as taxas de geração de viagem relacionando-se o volume diário com o número de passageiros, número de aeronaves e área total construída. De maneira geral observou-se uma taxa de 1,73 viagens por passageiro, considerando-se os dois terminais e somando-se os movimentos de entrada e saída e o número de passageiros embarcando e desembarcando, para o dia inteiro. A relação do total de viagens com a soma das aeronaves pousando e decolando no dia resultou numa taxa igual a 155,90. A taxa relacionando o número total de viagens por 100 metros quadrados de área de terminal foi 80,67 , neste caso considerando-se a soma das áreas dos dois terminais.

Para o horário de pico estas taxas foram 1,66 viagens por passageiro e 180,22 viagens por aeronave, respectivamente.

O valor elevado das taxas relacionadas com o volume de passageiros, próxima a dois, reforça a informação já relatada do significativo uso do automóvel em relação aos meios de transporte coletivos.

$\mathrm{O}$ alto valor das taxas relacionadas com o número de aeronaves indica que os voos tem uma ocupação elevada, demonstrando a alta utilização do aeroporto pela população. 
Na realidade o aeroporto Salgado Filho tem um importante papel na região sul e é o principal polo do transporte aéreo não somente para Porto Alegre, mas para muitas cidades do estado de Rio Grande do Sul. Também conecta o sul do Brasil com o MERCOSUL e alguns outros países, através de seus voos internacionais. Embora com uma demanda elevada, o aeroporto ainda não opera na capacidade, principalmente devido ao terminal 1 , que foi inaugurado no ano 2001, e que absorve a maior parte do movimento.

As taxas de geração de viagens obtidas neste estudo servem para estimar a quantidade de viagens terrestres para o referido aeroporto, quando relacionadas com o número de passageiros ou aeronaves atuais e no futuro.

Várias são as maneiras de utilização das taxas elaboradas. Elas podem ser usadas adotando-se as que representam o dia inteiro multiplicado pelo PPH e utilizando-se a distribuição direcional para obter os movimentos de entrada e saída separadamente ou diretamente os dados referentes à Hora-Pico.

Essas taxas podem ser usadas para o estudo e dimensionamento do volume de tráfego nas vias de acesso ao aeroporto, para definição de capacidade e nível de serviço, assim como uma análise da situação atual do seu entorno.

Normalmente, utilizam-se os métodos do HCM-2010 (Highway Capacity Manual), e os volumes na hora-pico. Entretanto, com utilização das taxas diárias juntamente com as percentagens horárias obtidas na figura 6, pode-se calcular o nível de serviço para diferentes cenários. Tendo-se em mãos a projeção de crescimento do número de passageiros e aeronaves pode-se estimar o número de veículos no futuro e com isto testar cenários no médio e longo prazo.

Para o dimensionamento dos estacionamentos pode-se usar as taxas do horário de pico de entrada multiplicadas pelo valor do tempo médio de permanência na vaga de estacionamento. Entretanto, vale ressaltar que se necessita ainda de informações complementares, tal como a percentagem dos veículos que entram e se dirigem para os estacionamentos, pois consequentemente, o restante se dirige ao meio-fio de embarque/desembarque.

Espera-se que as informações obtidas sejam úteis ao planejador de transportes para no dimensionamento dos acessos terrestres e dos estacionamentos do aeroporto estudado, em 
caso de ampliação, e melhoramentos, bem como em caso de implantação ou expansão de aeroportos com características similares.

Acredita-se também que o estudo realizado no aeroporto Salgado Filho representa um passo inicial deste tipo de estudo, que possa ser replicado em outras cidades brasileiras e de outros países ibero-americanos, de modo a se obter taxas e modelos de geração de viagens para outras realidades, a serem pesquisadas e comparadas, bem como possa vir a fortalecer esta linha de pesquisa dentro da Rede Ibero-Americana de Estudos em Polos Geradores de Viagens.

\section{Referências}

Agência Nacional de Aviação Civil - ANAC (2009) Movimento operacional nos principais aeroportos brasileiros - Relatório anual. Disponível em www.anac.gov.br.

Alves, B. B. e Strambi, O. (2011) Escolha de modo no acesso terrestre a aeroportos considerando a confiabilidade do tempo de viagem. Revista Transportes, vol. 19, n. 1, pp. 68-76.

Coogan, M. A. (2008) Ground access to major airports by public transportation. Report 4 Transportation Research Board of the National Academies.

Goldner, L. G. e Andrade, L. G. (2003) Estudo do estacionamento de automóveis em aeroportos - o caso do aeroporto internacional Hercílio Luz. XIV Congresso Brasileiro de Transporte e Trânsito - ANTP, Vitória.

Goldner, L. G. e Andrade, L. G. (2004) Uma análise do aeroporto Salgado Filho como um polo gerador de tráfego. Revista dos Transportes Públicos, n. 102, pp. 87-97.

Goldner, L. G., Goldner, N. e Pedrozo, D. E. (2005a) Ground access mode choice for two major airports in southern Brazil. IX Air Transport Research Society World Conference, Rio de Janeiro.

Goldner, L. G., Goldner, N. e Pedrozo, D. E. (2005b) Parâmetros para o dimensionamento dos estacionamentos de automóveis em aeroportos brasileiros. XIX Congresso de Pesquisa e Ensino em Transportes - ANPET, Pernambuco.

Goldner, L. G., Pedrozo, D. E. e Goldner, N. (2004) Modelos de demanda dos estacionamentos de automóveis nos aeroportos brasileiros. XVIII Congresso de Pesquisa e Ensino em Transportes ANPET, Florianópolis.

Goldner, L. G. e Monteiro, A. R. (2011) Taxa de geração de viagens para aeroportos: estudo de caso no aeroporto Hercílio Luz em Florianópolis/SC. XXV Congresso da Pesquisa e Ensino em Transportes- ANPET, Belo Horizonte.

Gosling, G. D. (2008) Airport ground access: mode choice models. A synthesis of airport practice. Synthesis 5 - Transportation Research Board of the National Academies.

Goswami, A. K., Miller, J. S. e Hoel, L. A. (2009) Airport offsite passenger service facilities: an option for improving landside access - volume II: access characteristics and travel demand. Disponível em www.virginiadot.org. 
Empresa Brasileira de Infraestrutura Aeroportuária - INFRAERO (2012) Documento técnico não publicado. Disponível em www.infraero.gov.br.

Institute of Transportation Engineers - ITE (2008) Trip generation. 8th Edition, vol. 2. Washington: Publisher ITE.

Kouwenhoven, M. (2008) The role of accessibility in passengers' choice of airports. Disponível em www.internationaltransportforum.org.

Monteiro, A. R. (2010) Análise dos acessos terrestres em cenários futuros e impacto gerado: novo terminal aeroportuário de Florianópolis-SC. (Trabalho de Conclusão de Curso), Universidade Federal de Santa Catarina, Florianópolis.

Ruhl, T. A. e Trnavskis, B. (1998) Airport trip generation, ITE Journal, vol. 68, pp 24-31.

Shapiro, P. S. e Katzman, M. (1998) Relationships between airport activity and ground transportation needs. Transportation Research Record: Journal of the Transportation Research Board, $\mathrm{n}$. 1622, pp. 8-12.

Teixeira, M. J., Galves, M. L. e Martins, P. P. P. (2012) Aplicação do auxílio multicritério à decisão na escolha de opções de estacionamento para os usuários do aeroporto de Viracopos. XXVI Congresso da Pesquisa e Ensino em Transportes - ANPET, Joinville. 